\title{
Does the price multiplier effect also hold for stocks?
}

\author{
Sergei Maslov ${ }^{1}$ and Bertrand M. Roehner ${ }^{2}$
}

\begin{abstract}
The price multiplier effect provides precious insight into the behavior of investors during episodes of speculative trading. It tells us that the higher the price of an asset is (within a set of similar assets) the more its price is likely to increase during the upgoing phase of a speculative price peak. In short, instead of being risk averse, as is often assumed, investors rather seem to be "risk prone". While this effect is known to hold for several sorts of assets, it has not yet been possible to test it for stocks because the price of one share has no intrinsic significance which means that one cannot say that a stock $A$ is more expensive than a stock $B$ on the basis of its price. In this paper we show that the price-dividend ratio gives a good basis for assessing the price of stocks in an intrinsic way. When this alternative measure is used instead, it turns out that the price multiplier effect also holds for stocks, at least if one concentrates on samples of companies which are sufficiently homogeneous.
\end{abstract}

19 May 2003

Keywords: stock prices, speculation, real estate, price-dividend ratio

1: Department of Physics, Brookhaven National Laboratory, Upton, New York 11973; maslov@bnl.gov

2: Permanent affiliation: Institute for Theoretical and High Energy Physics, University of Paris.

Postal address to which correspondence should be sent:

Bertrand Roehner, LPTHE, University Paris 7, 2 place Jussieu, 75005 Paris, France.

E-mail: ROEHNER@LPTHE.JUSSIEU.FR

FAX: 33144277990

This research was done during a stay of this author as a visiting researcher at Brookhaven Lab in April-May 2003. 


\section{Introduction}

The price multiplier effect gives us an insight into the behavior of investors during a speculative price peak. It tells us that the higher the price of an asset, the higher the amplitude of the price peak by which we understand the ratio $A=p_{2} / p_{1}$ of the peak price $p_{2}$ to the initial price $p_{1}$. In short, highly priced items seem to attract speculative capital in the same way as a magnet would attract bits of iron. In previous works (see [1]) this effect was shown to hold (during speculative episodes) for items as diverse as real estate, collector's stamps, antiquarian books or rare coins. What do these items have in common? Firstly, all of them happen to experience price peaks of substantial amplitude (say $A>2$ ); a second common feature is the fact that an investor can select one item among similar ones at almost no cost. For instance, an investor in stamps can choose whether to buy 20 stamps valued approximately ten euros each or instead to buy a single stamp valued at 200 euros. The only cost involved will be the time it takes to make the selection (the transaction cost may be slightly different also but we will neglect this effect). In contrast, for commodities a very different situation prevails: for instance it is a very different matter to have a cargo of oil in the Persian Gulf valued at \$20/barrel, or one in the Gulf of Mexico valued at $\$ 25 /$ barrel for in this case there is not only a difference in price but also a difference in location; to substitute one cargo for another would involve substantial transportation costs.

A natural question is whether or not the price multiplier effect also holds for stocks. Answering that question is the purpose of this paper; it is not an easy problem for at least three reasons.

- First one has to define how to compare the price of two stocks. Whereas it makes sense to say that a given house in San Francisco costs twice as much as another of same size in Oklahoma City, it is meaningless to say that the price of an IBM stock is twice the price of a CISCO stock for, as we know, through stock splits stock prices can be reduced by an arbitrary factor almost overnight. To sum up, our very first task will be to define the price of stocks in an intrinsic way so that they can be compared one with another in a meaningful way.

- The second difficulty has to do with the diversity which is inherent to stock markets. In order to explain this point let us again consider the example of the two houses in San Francisco and Oklahoma City; despite their disparity the prices of the two assets are determined by the same set of rules, namely by the rules which govern residential property markets. On the contrary, two companies such as Yahoo (an Internet company) and Burlington Northern Santa Fe (a railroad company) belong to two very different worlds and it is unlikely that their stock prices will be determined by similar rules. Naturally, to some extent it is possible to remedy to this difficulty by selecting stocks from a specified sample. For instance one may consider stocks belonging to the Dow Jones Transportation index that all belong to the transportation industry. But even for such a restricted sample there will be companies as different as Delta Airlines and the above mentioned Burlington railroad company.

- The third difficulty stems from the well-know fact that stock prices have a much higher volatility than housing prices. For instance the stock price of Wall-Mart (a retail trade company) increased from \$ 0.12 in January 1980 to \$ 61 dollar in March 2002; once deflated this represents a multiplication by a factor 239. The case of Wal-Mart is by no means unique for as we know during the 1980-2000 time interval, not a few companies experienced huge price peaks, especially in the telecommunication and information technology sectors. Needless to say, price increases of such an amplitude are completely unheard of in the housing market; this illustrates the fact that stock prices are much more volatile than housing prices, a feature which is directly connected with the fact that transaction costs and transaction times in housing markets are larger than in stock markets by several orders of magnitude. Needless to say, the high volatility of stock prices will add a substantial amount of noise and make it more difficult to test the price multiplier effect.

In the second section, starting from the known case of real estate markets, we show how the price 


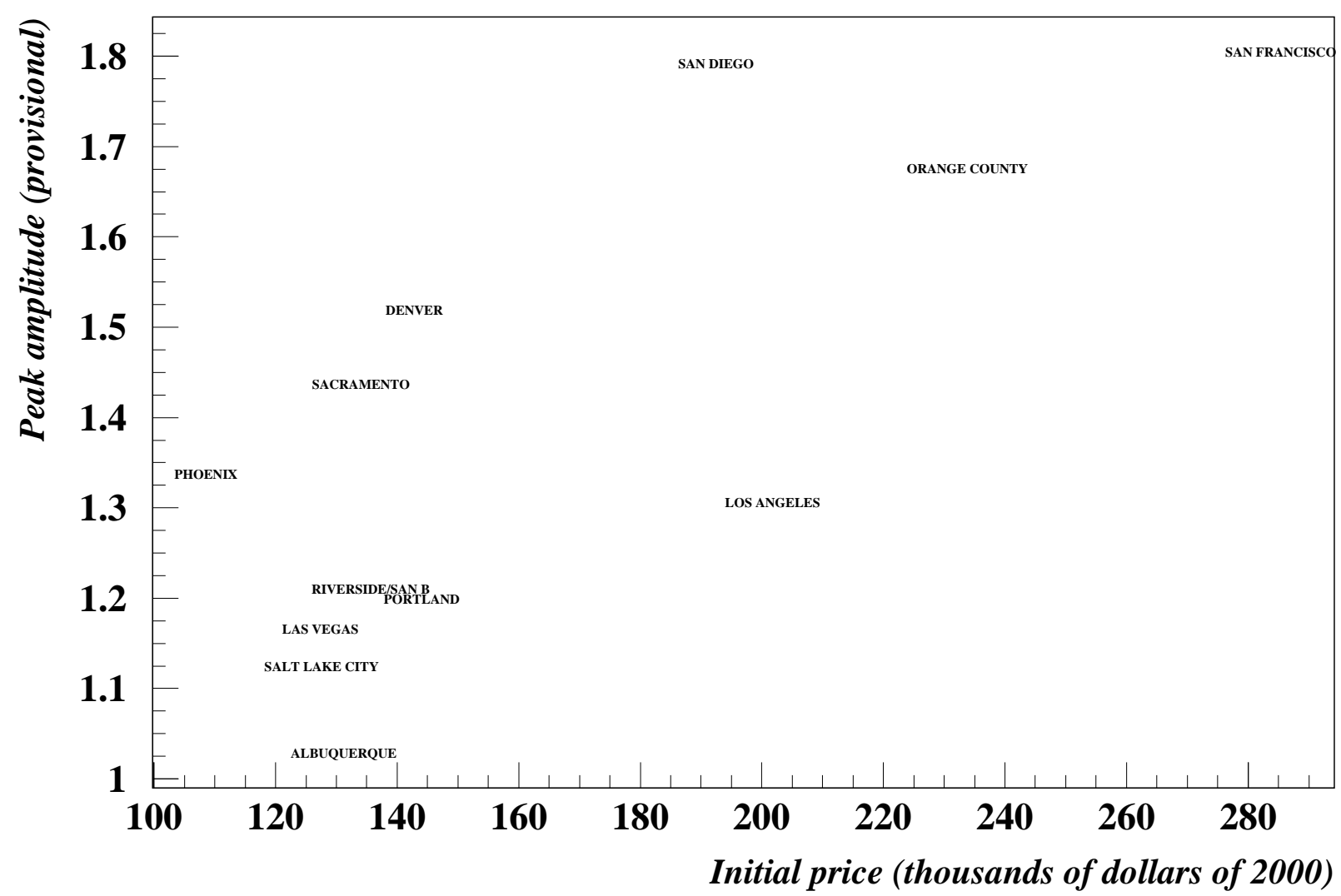

Fig.1: Correlation between initial housing prices and peak amplitudes, 1995-2002. The correlation is equal to 0.75. Source: Website of the California Association of Realtors.

multiplier effect can be extended to stocks. In the third section we explain why the price-dividend ratio can be seen as a convenient yardstick for assessing the respective value of stocks. Then in the fourth section we present the results of a several statistical tests of the price multiplier effect in stocks.

\section{From real estate to stocks}

First of all, in order for the reader to be able to develop an intuitive understanding of the price multiplier effect and its implications, we briefly illustrate it by way of an example. We consider housing prices in the West of the United States over the 1995-2002 time interval. Fig.1 shows that there is a significant correlation between initial prices in 12 major cities at the beginning of the price peak (that is to say in 1995) and the amplitudes of the price peaks; the correlation is equal to 0.75 with a confidence interval (at probability level 0.95 ) extending from 0.30 to 0.92 . For California alone (6 cities) the correlation is equal to 0.71 . It can be noted that these correlation levels are substantially higher than during the previous peak of 1984-1990; for California the correlation was then equal to only 0.60 (with a price increase of about 60 percent in San Francisco); moreover for the western cities located outside of California, prices showed no substantial increases (less than 10 percent over 6 years).

As an empirical rule, the level of the correlation in the price multiplier effect provides a measure of how widespread speculative trading is. If only we could know the proportion of transactions made by investors (as opposed to users), we would be able to check that rule directly; unfortunately such data do not seem to be available either for California or for any other housing market. The best possible check consists in observing that usually the higher the price peaks, the higher is also the correlation in the price multiplier effect. 
Regarding Fig.1 the reader may object that in 2002 prices in the West were still increasing and that the amplitudes shown in Fig. 1 represent only a proxy of the actual peak amplitudes. This is true; in fact, it is quite by purpose that we choose to present that case. It shows that we do not need to wait until all prices have peaked in order to test for the price multiplier effect. The obvious advantage of such a procedure is that it provides an assessment of the level of speculative trading at any moment during the upgoing phase. Naturally, in the first quarters of 1995 price increases were still small as was also the correlation of the price multiplier effect; but as speculative trading built up and gained momentum both price increases and correlation became more substantial.

At the beginning of the paper we pointed out that the major obstacle for extending the price multiplier effect to stocks is the fact that stock prices have no intrinsic meaning. Can we reformulate the price multiplier effect in the case of housing markets by substituting another variable to initial housing prices? The answer is yes: as will be seen, prices can be replaced by price-rent ratios, the latter being defined as the the ratio of the price of the house (or the apartment) to the annual rent paid by the tenant. This substitution is justified by the two following observations.

- Prices are correlated with price-rent ratios. This can be illustrated by resorting again to the case of the West in the U.S. For 18 cities the correlation between prices and price-rent ratios was equal to 0.66 in May 2001 and to 0.88 in May 2002 (more details can be found in [2]).

- Fig. 2 shows that during a speculative price peak, price and price-rent ratio move in parallel. Thus, the evolution in the course of time can be described either through price changes or through variations in the price-rent ratio. In the legend of Fig. 2 we used the expression price earnings ratio in order to underline the parallel with the price-earnings ratio of stocks. The fact that the price-rent ratio increases in the ascending phase shows that rents either increase slower than prices or even decrease. Direct evidence of a decrease can be found in New York City during the price peak of 2001-2002: between mid-2001 and the end of 2002, rents on average decreased by 15 percent while at the same time prices increased by about 20 percent (New York Times May 23, 2002, p.B9).

In short, at least during speculative episodes, prices and price-rent ratios are strongly connected both temporally and spatially; the great advantage of this observation comes from the fact that, in contrast to prices, price-rent ratios can be defined in an intrinsic way also for stocks. This is the point to which we come now.

\section{Defining a yardstick for the price of stocks}

The yardstick we wish to define should be able to tell us whether a stock $A$ is cheaper or more expensive than a stock $B$, but that yardstick only needs to apply to periods of speculative price peaks. Fig. 3 a,b,c,d shows that during such episodes prices and price-dividend ratios move in parallel ways. The definition of the price-dividend ratio used in these figures is the following:

$$
\operatorname{PDR}(t)=\frac{\text { Stock price at time } t}{\text { Dividends paid in the year preceding } t}
$$

The price-dividend ratio is very similar to the price earnings ratio but it has two clear advantages over the later (i) For a stock holder it is the quarterly dividend (rather than the earnings per share) which is is the analogue of the monthly rent received by an apartment owner from his (or her) tenant. (ii) Depending on the strategical accounting choices made by the direction of a company the profit in a given quarter can be reduced or inflated; for instance writing off a major acquisition over four years instead of ten years would substantially lower the earnings. Naturally, the level of dividend payments are also partly affected by the strategy of the company, but at least the dividends represent real money and not just a line in the company's accounting books. As the saying goes "Paper profits are one 


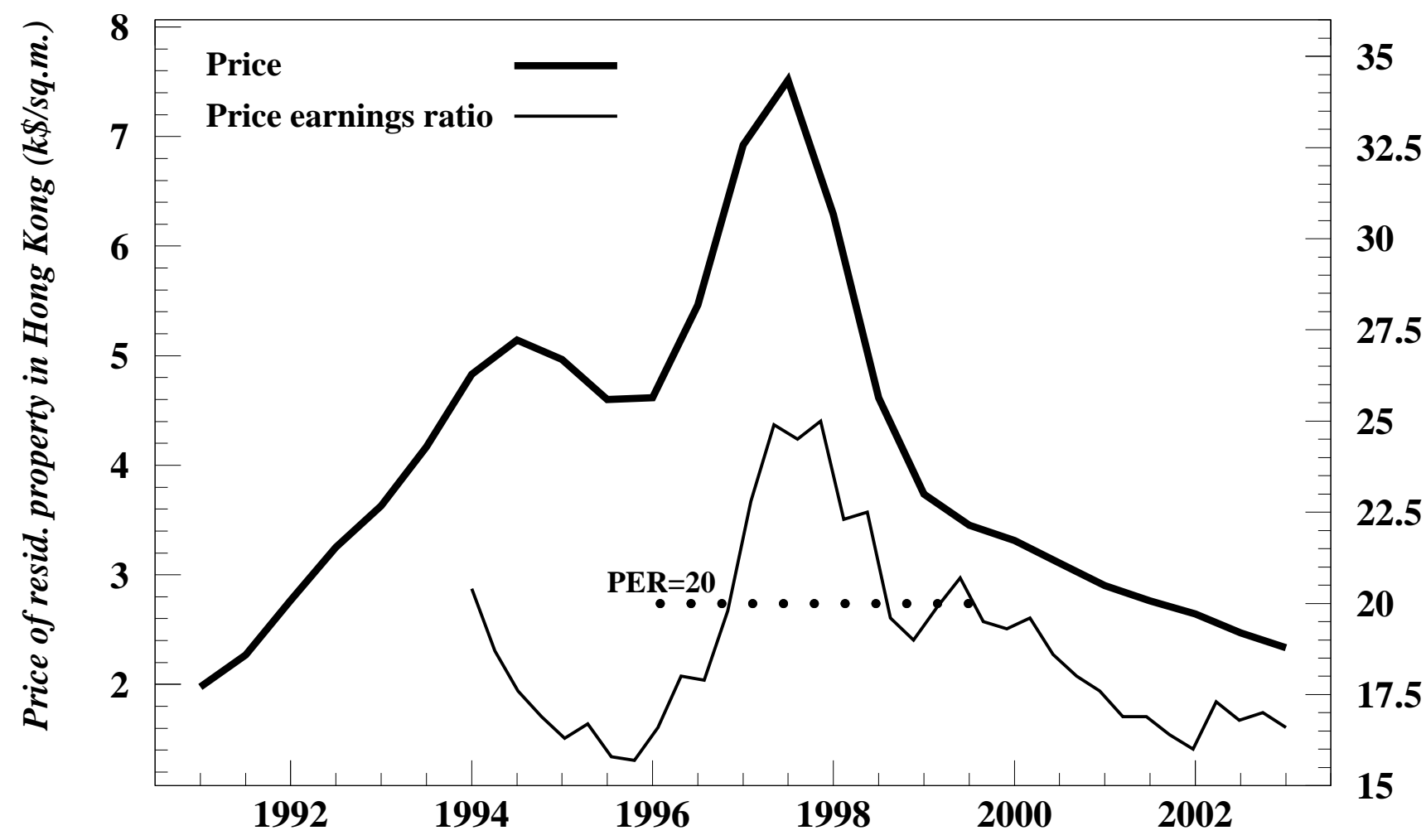

Fig.2: Price and price-rent ratio in Hong Kong during the speculative episode of 1992-2002 The prices are expressed in $10^{3}$ US\$ per square meter. When seen from the owner's (instead of tenant's) perspective the price-rent ratio should rather be called a price earnings ratio; this is why we used this expression in the graphic; it has the additional advantage of establishing a clear link with the price-earnings ratio of stocks. Source: Website of the Rating and Valuation Department of the Hong Kong Government.

thing, cash is another." In short, relying on dividends rather than on earnings seems to be a prudent and conservative approach.

On average in normal times companies distribute about 60 percent of their profit in the form of dividends, but for a company which wants to invest aggressively, that proportion may be much smaller. It can be noted that on the basis of 60 percent of the earnings being distributed to stockholders, the price-dividend ratio should be larger than the price earning ratio by a factor $1 / 0.60=1.70$. If, as is commonly admitted, the long term average of the price-earnings ratio over the last century is about 14 , the long term average of the PDR is around $14 \times 1.70=23$.

To sum up, the price-dividend ratio fulfills all the requirements that one may wish for a yardstick of stock prices. (i) During speculative episodes, PDR and stock price move in parallel. (ii) Seen from the side of the investor, the PDR is the exact analogue of the ratio of housing price to annual rent; it tells the investor in how many years its purchase (whether it is a house or a stock) will be covered by the flow of rents or dividends. In short, it provides a measure of how expensive the asset is with respect to future capital flow. (iii) The PDR (in contrast to the price-earnings ratio) can be measured in an objective and non-ambiguous way; furthermore long time series of dividend data are available in stock markets factbooks.

The question in the title of this paper about whether or not the price multiplier effect holds for stocks can therefore be rephrased in the following way: is there a relationship between initial PDR levels and amplitudes of price peaks? 

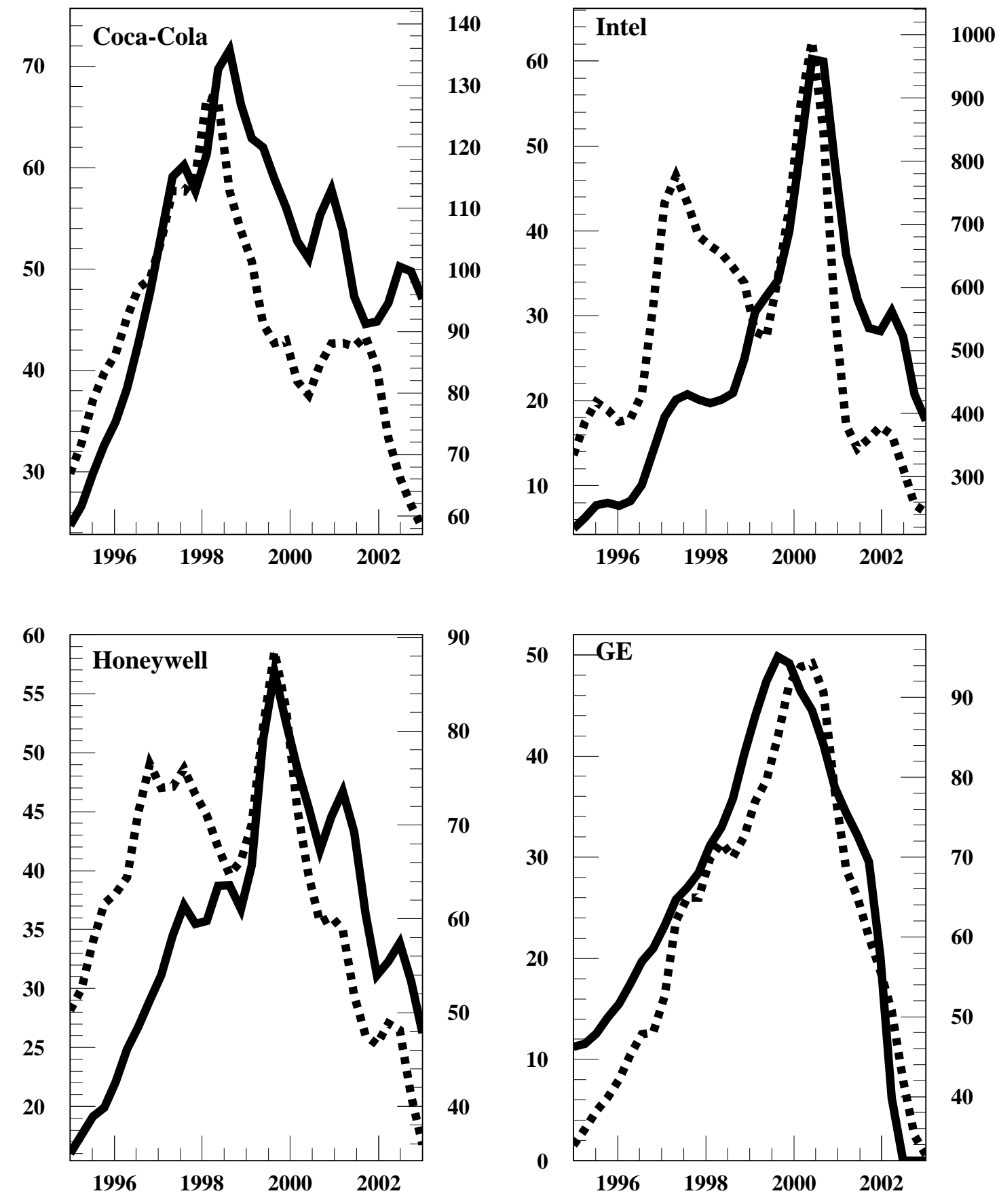

Fig.3 a,b,c,d: Price versus price-dividend ratio for four stocks. In the vicinity of the price peaks that occurred around 2000 the figure shows the respective evolution of the price (solid line and left-hand scale in dollars) and of the price-dividend ratio (broken line and right-hand side scale). The fact that the respective curves are fairly parallel shows that the level of the dividends remained fairly constant as prices experienced a sharp increase or decrease. Note the high level of the price-dividend ratio for Intel Corporation, which is typical of the small dividends distributed by the companies in the information technology. GE stands for General Electric. Source: http://finance.yahoo.com 


\section{Testing the price multiplier rule}

\subsection{Setting up the experiment}

Is there a significant correlation between levels of the price-dividend ratio at the start of a price peak and peak amplitudes, this is the question we wish to investigate. However, there are about 3,000 companies traded on the New York Stock Exchange and the first question we must address is how to select the sample(s) on which the price multiplier effect will be tested.

There are several requirements. First, the selection must follow an objective criterion, for example we may consider all the companies of the Dow Jones (DJ) Industrial Index, or the first 30 companies of the Standard and Poor's index arranged in alphabetical order. In order to limit the diversity of the sample we begin with the first choice. Besides the companies comprised in the Dow Jones Industrial Index we will also investigate other fairly homogeneous sets of companies such as those in the DJ Transportation index and the DJ Utility index.

The second question concerns the initial year, in other words when did the speculative price peak begin? A possible criterion would be to consider the largest time interval characterized by continuously positive annual price variations of stock indices. Such a criterion would put the beginning of the price peak around 1980. However, since the decade before 1980 was a bear market marked by substantial price falls, one may argue that during the early 1980s the market was merely catching up. Whatever the validity of such a reasoning, it would anyway be difficult to say with any degree of certainty whether the price peak has begun in 1985, 1990 or 1995 . This is why we will investigate all these dates in the hope that the comparison of the different results may give a better insight.

Remark Special dividends may be paid to stockholders on particular occasions, for instance when the company sells a subsidiary. In some cases these special dividends are very large compared to normal quarterly dividends. For instance, in May 1998 General Motors paid a \$14.33 special dividend which represented 7 times the annual dividend paid in previous or later years; other examples are Eastman Kodak which in January 1994 paid a special dividend equal to 6 times the annual dividend or At\&T which in October 2001 paid a special dividend equal to 11 times the annual dividend. Clearly special dividends of such an order of magnitude tend to disrupt the normal pattern of quarterly dividends over periods of time which are of the order of one decade; thus, in order to avoid any bias we discarded the companies and periods of time during which huge special dividends were distributed.

\subsection{Results}

The relationship between price-dividend ratios and peak amplitudes is summarized in Fig.4a,b,c,d for the four initial years 1980, 1985, 1990, 1995. For 1980 the correlation is almost completely due to Wal-Mart; moreover, the regression slope is much at variance with the results for the other three years. Naturally, one would expect that the slope of the regression becomes smaller when the initial date which is selected approaches the date of the peak which is somewhere between 2000 and 2002, and this is indeed the trend that we observe.

The significant correlation in cases 2 and 3 (see table 1) shows that the price multiplier rule applies to the stocks in the DJ Industrial index whether one takes 1985 or 1990 as the initial year. For 1995 as the initial year, one observes the same effect, but there is little interest in considering such a late starting point when previous ones work as well.

We now turn to the companies in the DJ Transportation and Utility indexes. The first index comprises 20 stocks, while the second contains only 15. In each case a few companies need to be discarded because the data are not available or because they did not pay dividends. We are therefore left with 

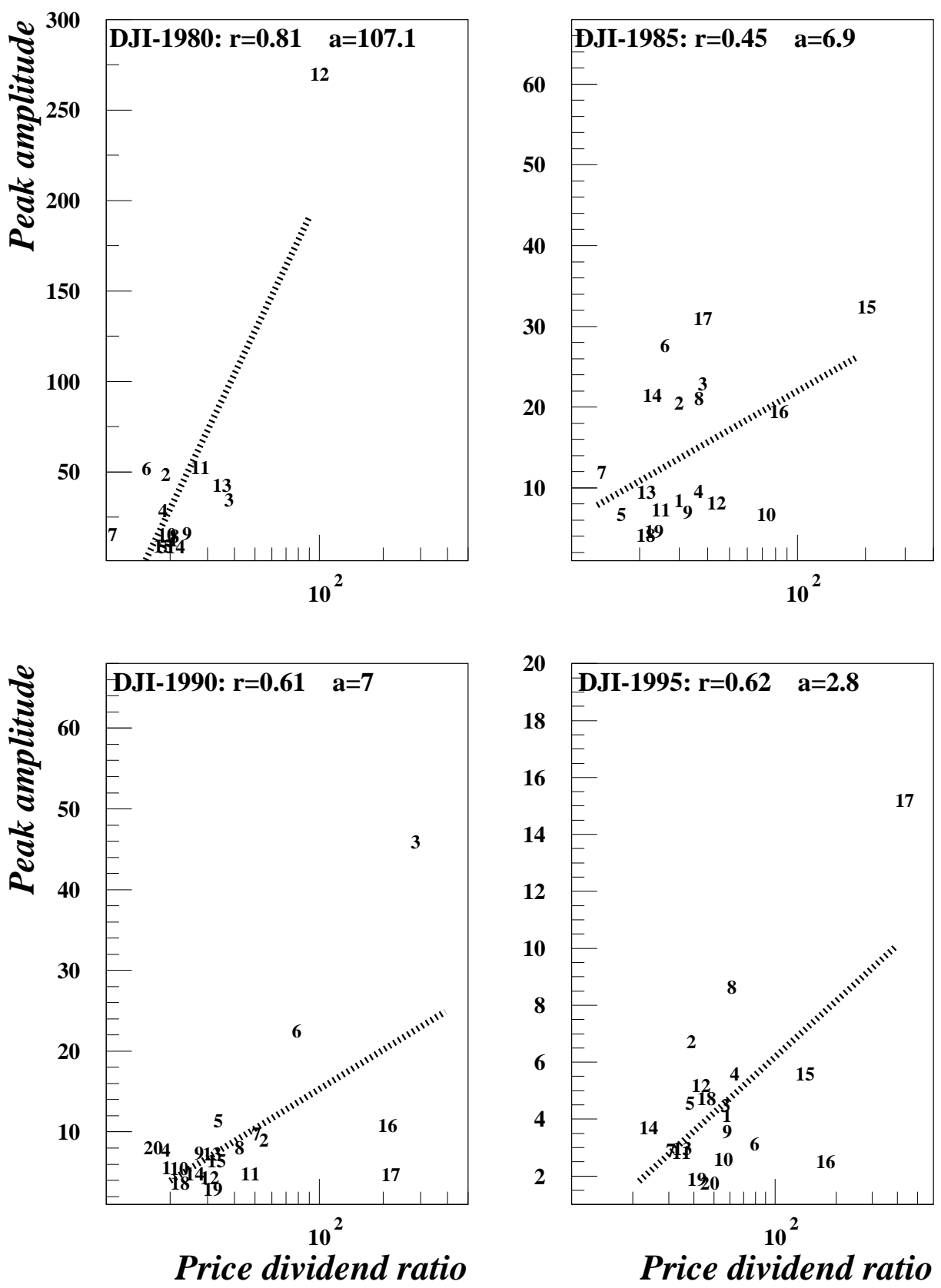

Fig.4 a,b,c,d: Correlation between initial price-dividend ratios and peak amplitudes. Horizontal axis: price-dividend ratio (logarithmic scale); vertical scale: amplitude of the price peaks. The stocks are those comprised in the DJ Industrial index and for which price and dividend data were available on the Yahoo website. In all cases there is a correlation which is significant at probability level 0.95 ; however, the scatter plots for 1980 and 1995 are dominated by a few outliers. On the scatter plots each number represents a company; the link with standard New Stock Exchange symbol names is as follows (full company names can be found on any financial website such as for instance finance.yahoo.com). 1980: $1=\mathrm{AA}, 2=\mathrm{GE}, 3=\mathrm{JNJ}, 4=\mathrm{AXP}, 5=\mathrm{GM}, 6=\mathrm{KO}, 7=\mathrm{T}$, $8=$ MMM, $9=$ UTX, 10=DD, $11=$ MO, 12=WMT, 13=MRK, 14=EK, 15=IP 1985: 1=AA, 2=GE, 3=JNJ, 4=AXP, $5=$ JPM, $6=\mathrm{KO}, 7=\mathrm{SBC}, 8=\mathrm{C}, 9=\mathrm{HON}, 10=\mathrm{CAT}, 11=\mathrm{MMM}, 12=\mathrm{UTX}, 13=\mathrm{DD}, \mathrm{C} 14=\mathrm{MO}, 15=\mathrm{WMT}, 16=\mathrm{DIS}, 17=\mathrm{MRK}, 18=\mathrm{EK}$, 19=IP 1990: $1=\mathrm{AA}, 2=\mathrm{KO}, 3=\mathrm{INTC}, 4=\mathrm{HON}, 5=\mathrm{GE}, 6=\mathrm{C}, 7=\mathrm{JNJ}, 8=\mathrm{MRK}, 9=\mathrm{AXP}, 10=\mathrm{SBC}, \mathrm{C} 11=\mathrm{CAT}, 12=\mathrm{MMM}$, 13=UTX, 14=DD, 15=MO, 16=WMT, 17=DIS, 18=EK, 19=IP, 20=JPM 1995: 1=AA, 2=GE, 3=JNJ, 4=AXP, 5=JPM, $6=\mathrm{KO}, 7=\mathrm{SBC}, 8=\mathrm{C}, 9=\mathrm{HON}, 10=\mathrm{CAT}, 11=\mathrm{MMM}, 12=\mathrm{UTX}, 13=\mathrm{DD}, 14=\mathrm{MO}, 15=\mathrm{WMT}, 16=\mathrm{DIS}, 17=\mathrm{INTC}, 18=\mathrm{MRK}$, $19=\mathrm{EK}, 20=\mathrm{IP}$. 


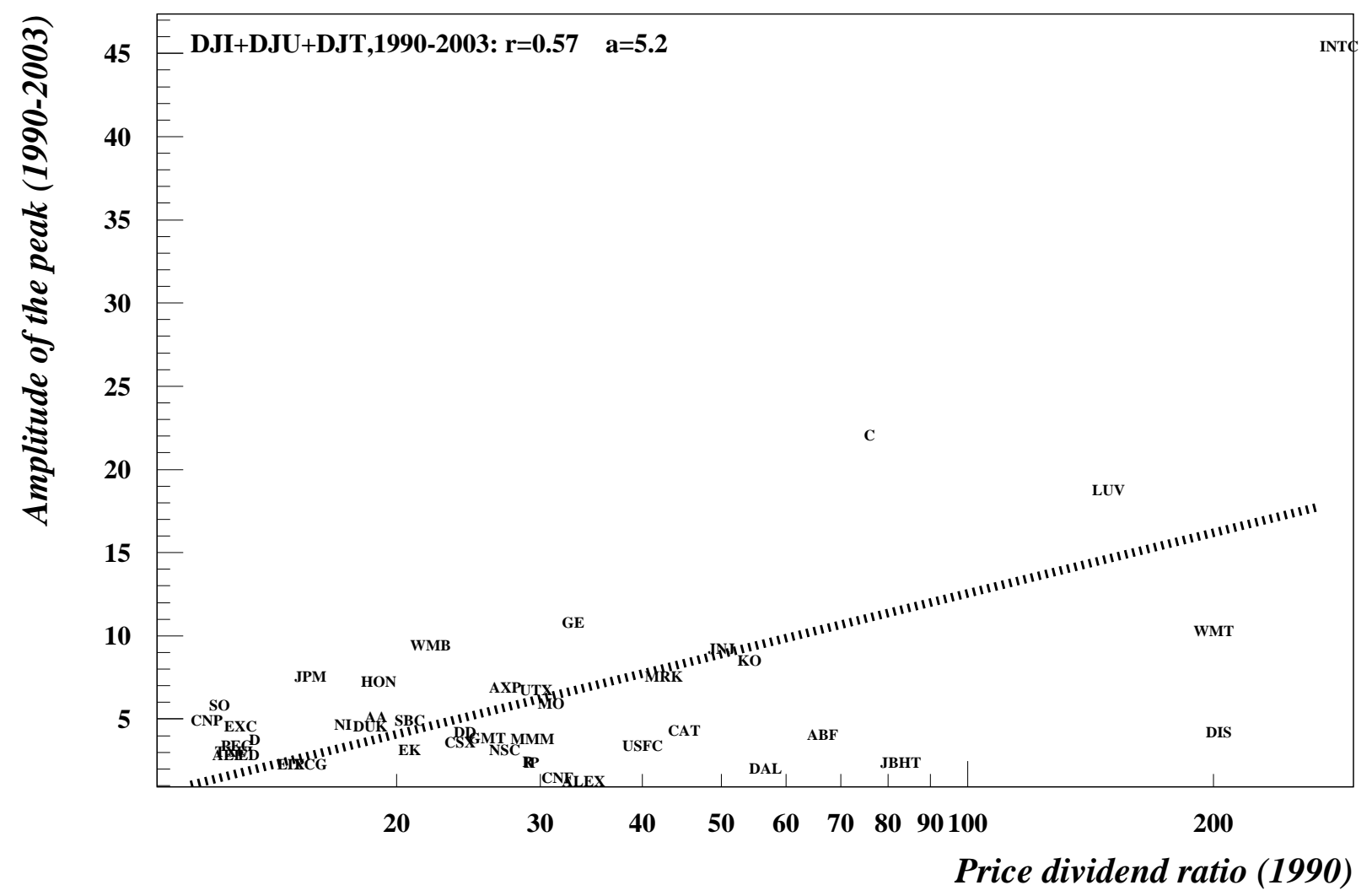

Fig.5: Correlation between initial price-dividend ratios and peak amplitudes. The stocks are those comprised in the DJ Industrial, DJ Transportation and DJ Utility indexes for which price and dividend data were available on the Yahoo website. Source: http://finance.yahoo.com.

samples which are fairly small; as a result, the correlations although positive have broad confidence intervals (see table 1). In order to get a more significant result we have grouped together all the stocks of the DJI, DJT and DJU; the corresponding graph is shown in Fig.5. On the one hand, the dispersion is increased because the sample is less homogeneous, but on the other hand we now have a sample comprising 44 stocks which results in reduced confidence intervals for both the correlation and the regression coefficients.

In the next test we relaxed the homogeneity criterion and considered a sample of companies drawn at random from the set of 500 companies that make up the Standard and Poor's index. In this case the correlation breaks down; table 1 shows that for 1990 at the starting year it is almost zero, whereas for 1995 it is slightly positive but barely significant. It must be said that what makes the matter worse is the fact that many of those companies in the information technology sector which experienced huge price increases did not pay any dividend at all; in other words their PDR was basically infinite and we cannot include these stocks into our sample. In short, the cases which would provide the most compelling evidence unfortunately must be left out of the statistical analysis.

\section{Conclusion}

Previous studies have shown that the strength of the price multiplier effect that is to say the level of the correlation between initial prices and peak amplitudes can be seen as a measure of the amount of speculative trading (as distinct from trades performed by users) which is going on in a market. As on stock markets there are no users at all (nobody buys a stock just to "use it"); one would expect the 
Table 1 Correlation between price-dividend ratio and peak amplitude: Amplitude $=a \log (\mathrm{PDR})+b$

\begin{tabular}{clcccccc}
$\begin{array}{c}\text { Case } \\
\text { number }\end{array}$ & Sample & $\begin{array}{c}\text { Initial } \\
\text { year }\end{array}$ & $\begin{array}{c}\text { Number } \\
\text { of stocks }\end{array}$ & Correlation & $\begin{array}{c}\text { Confidence } \\
\text { interval }\end{array}$ & $a$ & $b$ \\
\hline 1 & DJI & 1980 & 15 & 0.82 & $0.53,0.94$ & $107 \pm 41$ & $-291 \pm 20$ \\
2 & DJI & 1985 & 19 & 0.46 & $0.003,0.75$ & $6.9 \pm 6$ & $-10 \pm 4$ \\
3 & DJI & 1990 & 20 & 0.62 & $0.24,0.83$ & $7.0 \pm 4$ & $-17 \pm 3$ \\
4 & DJI & 1995 & 20 & 0.63 & $0.26,0.84$ & $2.8 \pm 1$ & $-6.9 \pm 1$ \\
5 & DJT & 1990 & 11 & 0.69 & $0.15,0.91$ & $5.8 \pm 4$ & $-18 \pm 2$ \\
6 & DJU & 1990 & 13 & 0.52 & $-0.04,0.83$ & $5.3 \pm 5$ & $-10 \pm 1$ \\
7 & DJI+DJT+DJU & 1990 & 44 & 0.58 & $0.34,0.75$ & $5.2 \pm 2$ & $-11 \pm 2$ \\
8 & S\&P500 & 1990 & 60 & -0.03 & $-0.28,0.22$ & & \\
9 & S\&P500 & 1995 & 60 & 0.26 & $0.005,0.48$ & &
\end{tabular}

Average

0.54

5.5

12

Notes: One must keep in mind the fact that because many of the high tech companies whose price shot up in the 1990s did not distribute any dividend, they cannot be included in our samples; this is of particular importance for the smaller companies considered in the S\&P500 cases, but it also concerns a few major companies in the DJI sample (Microsoft in one example). In a few number of cases (IBM is one of the main examples) dividends were duly distributed but for some reason are not recorded in the Yahoo database. When computing the average of the regression coefficients $a$ and $b$ we discarded the first case which is obviously an outlier.

Source: http://finance.yahoo.com

price multiplier effect to apply to stocks even better than it applies to other assets. However, for a number of reasons ranging from the high levels of noise and volatility to the dwindling importance of dividends, the experimental test is far from being straightforward. Nevertheless, when conducted in a proper way observation shows that the price multiplier effect also holds for stocks provided initial price-dividend ratios are substituted for initial prices.

At this point an observation is in order regarding the dwindling role of dividends. In recent times, companies more and more tended to replace dividends by other gratifications among which buyback of shares is the most important. Usually companies buy back their own shares at a price which is slightly higher than the market price; this represents a one-time payment which can be seen as a special dividend replacing the payment of quarterly dividends. Over the past five or six years, major companies such as Citigroup or IBM have devoted billions of dollars to buyback programs; it is estimated that over this time interval buybacks represented 1.3 trillion dollars that is to say approximately 10 percent of the capitalization of the New York Stock Exchange in 2001 (source: Trimtabs.com cited in WallstreetWishList.com). At the other end of the pipe, new stocks are constantly created for instance through the distribution of stock options, that is to say the right to buy a given amount of stocks at a preset price and date. Currently, the distribution of stock options is limited mainly to employees, but one could imagine stock holders to be rewarded in a similar way. That would have the obvious advantage of giving stock holders a strong incentive for pushing up stock prices.

At the present time it is difficult to say whether markets will continue to move in this direction. If they do this would represent a significant watershed with respect to the way stock markets have been operating during the past two centuries. With dividends losing much of their importance, investors 
would increasingly have to rely on capital gains. In other words, instead of being a cash flow asset like commercial or residential property, stocks would tend to become an asset similar to rare coins, collector stamps or antiquarian books. If it continues such an evolution would significantly change the behavior of stock holders during speculative episodes which was the topic that we investigated in this paper.

Acknowledgement We express our gratitude to Professor Bruce Mizrach for his kind assistance regarding data sets for dividends.

\section{References}

[1] Roehner (B.M.) 2000: Speculative trading: the price multiplier effect. The European Physical Journal B 14, 395-399. Roehner (B.M.) 2001: Hidden collective factors in speculative trading. Springer-Verlag. Berlin (chapter 6).

[2] Roehner (B.M.) 2003: Patterns of speculation in real estate and stocks. in Proceedings of the Nikkei Workshop in Econophysics (Tokyo, November 2002). Springer-Verlag. Berling. in press. 